Article

\title{
Evaluating Water Resource Security in Karst Areas Using DPSIRM Modeling, Gray Correlation, and Matter-Element Analysis
}

\author{
Deliang Sun ${ }^{1,2,3}$, Jianping Wu ${ }^{1,2, *}$, Fengtai Zhang ${ }^{4, *}$, Weici Su ${ }^{3}$ and Hong Hui ${ }^{4}$ \\ 1 Key Laboratory of Geographic Information Science (Ministry of Education), East China Normal University, \\ Shanghai 200241, China; sundeliang2002@aliyun.com \\ 2 School of Geographic Sciences, East China Normal University, Shanghai 200241, China \\ 3 School of Geography Science \& Tourism, Chongqing Normal University, Chongqing 400047, China; \\ suweici@sina.com \\ 4 School of Management, Chongqing University of Technology, Chongqing 400054, China; hhzrj@hotmail.com \\ * Correspondence: jpwu@geo.ecnu.edu.cn (J.W.); zhfthero45@cqut.edu.cn (F.Z.)
}

Received: 13 July 2018; Accepted: 25 October 2018; Published: 29 October 2018

\begin{abstract}
To evaluate the long-term security of water resources in Guizhou, this paper presents an evaluation index that incorporates the driving force-pressure-state-impact-response-management (DPSIRM) framework, the gray correlation method, and matter-element analysis. For the period of 2005-2012, our results show that water resources were within the "generally safe" limits for all years except 2006 and 2011, which were characterized by drought conditions. In karst regions, drought has a relatively large impact on water security and is compounded in Guizhou by rapid economic development, nonpoint-source agricultural pollution, and inadequate sewage treatment. Nonetheless, recent efforts to return farmland to forest and grassland and to control desertification have led to increased forest cover and higher levels of soil and water conservation, while systems have been implemented to foster the effective management of water resources in karst areas. In this study, we used both gray matter-element analysis and a DPSIRM framework to assess the state of water resources in Guizhou, the results of which were compared and verified by the gray set pair method, and to provide a reference for evaluating other karst areas.
\end{abstract}

Keywords: water resource security; DPSIRM model; gray matter-element analysis; karst area

\section{Introduction}

Societies require water for drinking, irrigation, and industry [1,2]. Yet, in many parts of the world, demand has surpassed supply, and the availability and quality of freshwater has become severely restricted [3]. This has resulted in conflict as a growing number of users compete for limited resources [4,5]. A logical approach to tackling the global water crisis is the improved management of available resources [6,7], specifically, the quantitative assessment of regional water security and a better understanding of the factors influencing the water supply.

China ranked 121st in a 2011 study of water use per capita [8] and is in the top 13 countries with insufficient water availability. Consequently, water resource security has become a principal factor limiting economic and social development in China. To date, water security evaluations have focused on regions traditionally associated with water scarcity [9], such as the populous areas of Central and Eastern China [10,11], the arid northwest, and the Yellow River Basin [12]. In contrast, little attention has been paid to water availability in the country's humid, economically deprived southwestern areas, which includes China's famous karst region. Despite abundant rainfall in these areas because 
of the karstic nature of the landscape, water resources are frequently unable to meet the growing local demand.

Over the last decade, numerous evaluation methods have been developed to assess water resource security, including the pressure-state-response (PSR) framework [13,14], the drive-pressure-status-impact-response (DPSIR) model [15-18], fuzzy comprehensive evaluation [19], analytic hierarchy processing (AHP) [20], the entropy weight [21] and water footprint [22] methods, and set pair analysis [23]. While these methods have undoubtedly contributed to our understanding of water security, their efficacy is limited by several key factors. First, index selection is one-sided and accounts for neither the process of water resource evolution nor its internal mechanisms. Second, index weight relies on user experience, making the process inherently subjective and raising the possibility that objective data will be missed. Third, existing methods ignore the relationships between single indicators and specific security levels [24,25].

Based on the gray system theory, the gray correlation method provides a mathematical basis to assess objectivity without subjectivity and is more reasonable for determining the weights. In its current form, the gray correlation method has not been used extensively in water security research. In contrast, matter-element analysis, which is based on the subordinate relationship between a single index and a rating, integrates the security rating of the evaluation object and, thus, reflects the internal evolution and mechanisms of water resources. The DPSIR-management (DPSIRM) framework includes the economic, social, ecological, and environmental factors affecting water security. This approach describes the internal mechanism of water security evolution and highlights the various environmental-resource-human interactions involved, as well as emphasizing the importance of water security management.

The predominant objectives of this study are (1) to construct a DPSIRM model of index systems used to evaluate water security in karst areas, (2) to combine and use a gray correlation-matter element to assess water resource security in Guizhou province, (3) to explore the quantitative evaluation index systems and suitable methods of water security in the karst area and assess the impact of environmental factors on water availability, and (4) to thereby provide a theoretical and methodological reference point for future research.

\section{Materials and Methods}

\subsection{Study Area}

Guizhou province, in Southwest China $\left(37^{\circ} 24^{\prime}-13^{\circ} 29^{\prime} \mathrm{N}, 103^{\circ} 36^{\prime}-109^{\circ} 35^{\prime}\right.$ E) (Figure 1), is characterized by a karst landscape that-along with the neighboring provinces of Guangxi, Yunnan, Sichuan, Chongqing, Hubei, and Hunan-forms the largest karst region on earth. Seventy-three percent of the land area of Guizhou is karst, in which water availability is the principal limiting factor for ecosystem health. Located in the upper reaches of both the Yangtze River and Pearl River Basins (China's two most economically developed regions), the province is located in the position of the plateau water tower, and its ecological environment is very important. The province is also highly diverse ethnically, with 49 nationalities and 48 ethnic minorities accounting for $37.9 \%$ of the total population. Yet, Guizhou province lags behind the rest of China economically, ranking 29th in terms GDP (10,502.56 billion yuan) and per capita income (33,242 yuan) in 2016. Ultimately, the problem of water availability relates not only to Guizhou's economic, social, and ecological security but also to the viability of development along the Yangtze and Pearl Rivers. 


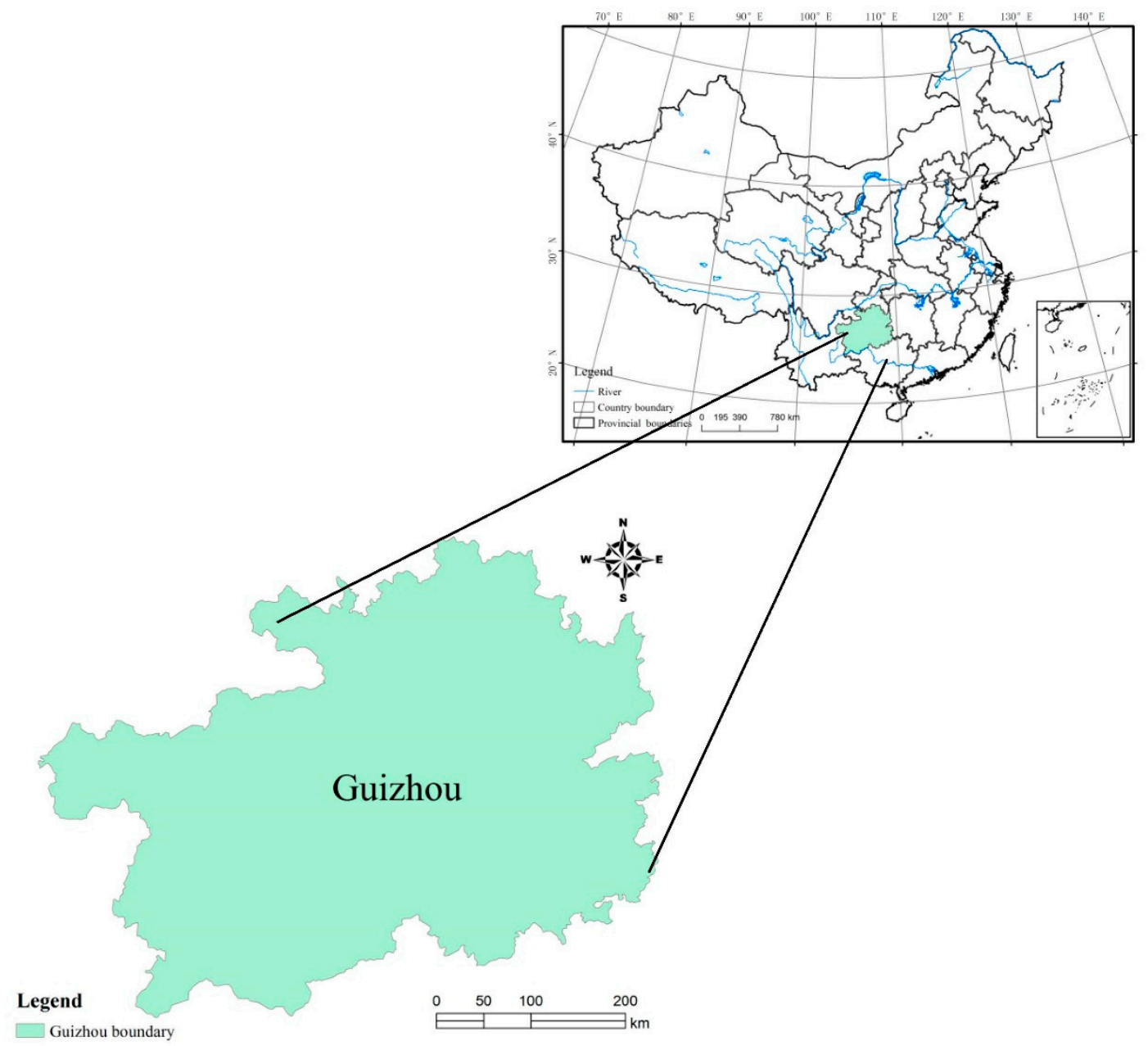

Figure 1. Location of the Guizhou study area.

\subsection{Data Source}

Input data for the period of 2005-2012 were sourced primarily from the "Water Resources Bulletin of Guizhou Province" and the "Environmental Protection Bulletin of Guizhou Province", which are published on the websites of the Guizhou Provincial Water Resources Department and the Environmental Protection Bureau of Guizhou province, respectively, and from the "Statistical Yearbook of Guizhou Province". Additional data were acquired via expert scoring and trend forecasting.

\subsection{DPSIRM Framework for Water Security}

The PSR framework, conceived in the 1970s by Statistics Canada, was an early causal model for making one-to-one linkages among various stresses, environmental changes, and societal responses [14,15]. The PSR framework is still widely used and continues to evolve. For instance, the DPSIR model [16] was established by the Organization of Economic Cooperation and Development $[7,13]$ as a PSR extension designed to capture "cause-effect" relationships among the various sectors of social, economic, and environmental systems. The model describes a general chain that triggers environmental issues between the origin and the outcome, and although it does not account for management, the model has been used widely in the analysis of human-environment interactions.

Because water is a finite resource and subject to the effects of pollution and climate, the effective management of water resources is crucial to improving regional water security and thus must be included in security evaluations. At present, the DPSIRM model is rare in water resource security evaluations. The karst area is rich in precipitation resources but, due to special geological conditions, 
the groundwater resources are rich, and the surface water resources are limited as they belong to the engineering water shortage area. Therefore, water resource management in karst areas is particularly important. Accordingly, we incorporated water resource management into the DPSIR framework to produce the DPSIRM evaluation index, a complex causal framework designed to represent regional water security more accurately.

The DPSIRM framework consists of six parts, or submodels: the driver, pressure, state, impact, response, and management submodels. As shown in Figure 2, driving factors (D) include regional population and economic and social development, all of which present real challenges for managing water resources in karst regions. The pressure $(\mathrm{P})$ mainly includes the actual water intensity of overall economic, industrial, and agricultural development, as well as the pressure on water resources caused by pollutant emissions from industrial and agricultural development. The states (S) mainly include the current water resource supply per capita and per unit area and the environmental status indicators that indirectly reflect water resource distribution characteristics in karst areas, such as "the rate of rocky desertification". The impact (I) mainly includes the changes in water quality and the quantity impact on the environment and the economy of karst areas, such as "river index rate", "drought and drought damage as a share of GDP", and "modulus of sediment yield". The responses (R) mainly include reflection and technological progress in response to changes in the quality and quantity of water resources, such as "sewage treatment rate" and "water resource development rate". Management (M) mainly includes policies and measures adopted in response to drive, pressure, state, impact, and response. In the current situation of limited water resources in karst areas, water resource management is the key to solve the problem of water resource security. The changes in water quality and quantity, the tension between supply and demand of water resources, and fears over water resource security are all factors that highlight the need to strengthen global and regional water resource management. The specific indicators are shown in Table 1.

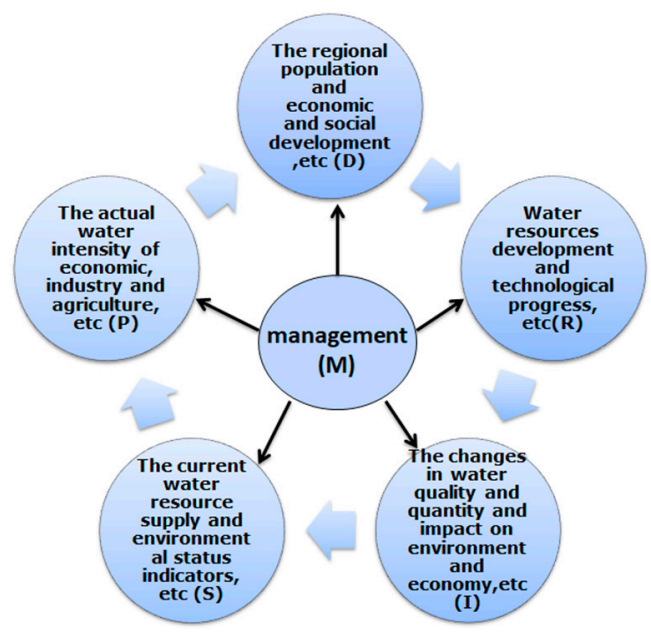

Figure 2. Driving force-pressure-state-impact-response-management (DPSIRM) model framework for evaluating water resource security. 
Table 1. Water safety indexes and their meanings.

\begin{tabular}{|c|c|c|c|c|c|}
\hline $\begin{array}{l}\text { Target } \\
\text { Layer }\end{array}$ & Factor Layer & Index Layer & Weight & $\begin{array}{l}\text { Weight of } \\
\text { Item }\end{array}$ & Meaning \\
\hline \multirow{24}{*}{$\begin{array}{l}\text { Water } \\
\text { Resource } \\
\text { Security }\end{array}$} & \multirow{5}{*}{$\begin{array}{l}\text { Driving forces } \\
\text { (D) }\end{array}$} & Per capita GDP (yuan/person) & 0.036 & 0.178 & $\begin{array}{c}\text { Driving force of economic } \\
\text { development on water security }\end{array}$ \\
\hline & & Population density (people $/ \mathrm{km}^{2}$ ) & 0.043 & 0.214 & $\begin{array}{l}\text { Driving force of population } \\
\text { density on water security }\end{array}$ \\
\hline & & Urbanization rate (\%) & 0.044 & 0.220 & $\begin{array}{c}\text { Driving force of regional } \\
\text { development on water security }\end{array}$ \\
\hline & & $\begin{array}{l}\text { Area of irrigated land that is the } \\
\text { proportion of cultivated area (\%) }\end{array}$ & 0.041 & 0.203 & $\begin{array}{l}\text { Driving force of agricultural } \\
\text { development on water security }\end{array}$ \\
\hline & & Annual growth rate of GDP (\%) & 0.037 & 0.184 & $\begin{array}{c}\text { Driving force of economic } \\
\text { development intensity on water } \\
\text { security }\end{array}$ \\
\hline & \multirow{5}{*}{ Pressures (P) } & $\begin{array}{l}\text { Water consumption of } 10,000 \\
\text { yuan GDP (m } / 10,000 \text { yuan) }\end{array}$ & 0.041 & 0.200 & $\begin{array}{c}\text { Intensity of economic } \\
\text { development pressures on the } \\
\text { quantity of water resources }\end{array}$ \\
\hline & & $\begin{array}{l}\text { Amount of water used for the } \\
\text { industrial production of } 10,000 \\
\text { yuan }\left(\mathrm{m}^{3} / 10,000 \text { yuan) }\right.\end{array}$ & 0.035 & 0.173 & $\begin{array}{c}\text { Industrial water pressure on the } \\
\text { quantity of water resources }\end{array}$ \\
\hline & & $\begin{array}{l}\text { Water for agricultural production } \\
\qquad\left(\mathrm{m}^{3} / 10,000 \text { yuan }\right)\end{array}$ & 0.041 & 0.199 & $\begin{array}{l}\text { Agricultural water pressure on } \\
\text { the quantity of water resources }\end{array}$ \\
\hline & & $\begin{array}{l}\text { Discharge of waste water per unit } \\
\text { of industrial output } \\
\text { (t/10,000 yuan) }\end{array}$ & 0.045 & 0.223 & $\begin{array}{l}\text { Industrial production pressure on } \\
\text { the quality of water resources }\end{array}$ \\
\hline & & $\begin{array}{l}\text { Amount of fertilizer used per unit } \\
\text { of cultivated area }\left(\mathrm{kg} / \mathrm{hm}^{2}\right)\end{array}$ & 0.042 & 0.204 & $\begin{array}{l}\text { Agricultural production pressure } \\
\text { on the quality of water resources }\end{array}$ \\
\hline & \multirow{3}{*}{ States $(S)$} & Water per capita ( $\mathrm{m}^{3} /$ person) & 0.038 & 0.294 & Per capita state of water resources \\
\hline & & $\begin{array}{l}\text { Water resources per unit area } \\
\qquad\left(10^{4} \mathrm{~m}^{3} / \mathrm{km}^{2}\right)\end{array}$ & 0.046 & 0.357 & $\begin{array}{l}\text { Water resource state of the unit } \\
\text { land area }\end{array}$ \\
\hline & & Rate of rocky desertification (\%) & 0.045 & 0.349 & State of soil erosion \\
\hline & \multirow{4}{*}{ Impact (I) } & Forest coverage (\%) & 0.046 & 0.244 & $\begin{array}{l}\text { Impact on the surface storage } \\
\text { capacity }\end{array}$ \\
\hline & & River water quality index rate $(\%)$ & 0.042 & 0.226 & $\begin{array}{c}\text { Impact on the water quality of } \\
\text { rivers }\end{array}$ \\
\hline & & $\begin{array}{c}\text { Drought and drought damage as } \\
\text { a share of GDP }(\%)\end{array}$ & 0.059 & 0.318 & Impact on economy and society \\
\hline & & $\begin{array}{l}\text { Modulus of sediment yield } \\
\qquad\left(\mathrm{t} / \mathrm{km}^{2}\right)\end{array}$ & 0.039 & 0.212 & Impact on soil erosion \\
\hline & \multirow{3}{*}{ Responses (R) } & Sewage treatment rate $(\%)$ & 0.038 & 0.319 & Water quality response \\
\hline & & $\begin{array}{l}\text { Discharge standard-meeting rate } \\
\text { of industrial wastewaters (\%) }\end{array}$ & 0.037 & 0.318 & Water quality response \\
\hline & & $\begin{array}{l}\text { Water resource development rate } \\
(\%)\end{array}$ & 0.043 & 0.363 & Water quantity response \\
\hline & \multirow{4}{*}{$\begin{array}{l}\text { Management } \\
\text { (M) }\end{array}$} & $\begin{array}{c}\text { Environmental protection } \\
\text { investment as a percentage of } \\
\text { GDP }(\%)\end{array}$ & 0.044 & 0.268 & Adequacy of fund management \\
\hline & & $\begin{array}{l}\text { Integrity of the water protection } \\
\text { and management system }\end{array}$ & 0.041 & 0.248 & Integrity of management system \\
\hline & & $\begin{array}{l}\text { Implementation of the water } \\
\text { resource protection and } \\
\text { management system }\end{array}$ & 0.040 & 0.243 & Effectiveness of management \\
\hline & & $\begin{array}{c}\text { Information on flood control and } \\
\text { drought relief }\end{array}$ & 0.040 & 0.242 & $\begin{array}{c}\text { Communication of management } \\
\text { information }\end{array}$ \\
\hline
\end{tabular}

\subsection{The Gray Correlation Method}

As a new component of gray system theory, which is based on the degree of similarity or dissimilarity between factors, the gray correlation method is used to measure the correlation between factors $[24,26,27]$. It overcomes the subjective arbitrariness of traditionally subjective values (e.g., AHP) and can objectively assign weights when the index weight difference is too large $[28,29]$. The gray correlation method incorporates the objectivity of a mathematical model, although the coefficient 
reflects a certain degree of subjectivity, and it is thought to provide a closer determination of weight, making it suitable for enhancing water resource security indicators.

\subsubsection{Data Standardization}

To eliminate the physical dimension of each index's impact, we quantified the various indexes in the sample matrix prior to evaluation, using linear interpolation for the nondimensional processing of raw data. Then, to evaluate the water security of $n$ years in each area, we followed the original index data matrix approach of Zhang et al. (2015) [26] and Xia et al. (2016) [24].

$$
X=\left\{\begin{array}{cccc}
X_{11} & X_{12} & \cdots & X_{1 n} \\
X_{21} & X_{22} & \cdots & X_{11} \\
\vdots & \vdots & \vdots & \vdots \\
X_{m 1} & X_{m 2} & \cdots & X_{m n}
\end{array}\right\}
$$

stands for the original index.

In general, each indicator of water resource security can be divided into negative and positive indicators. For positive indicators, the bigger the value, the better. Their standardized calculation is

$$
y=\frac{X-X_{\min }}{X_{\max }-X_{\min }} .
$$

For negative indicators (cost indicators), the smaller the value, the better. Their standardized calculation is

$$
y=1-\frac{X-X_{\min }}{X_{\max }-X_{\min }}
$$

where $y$ stands for the normalized index, and $X_{\max }$ and $X_{\min }$ represent maximum and minimum index values, respectively.

\subsubsection{Determining the Optimal Vector of the Sequence}

Due to the standardization of raw data, the optimal vector is as follows (Zhang et al., 2015):

$$
G=\left(g_{1}, g_{2}, \cdots g_{n}\right)=\left(y_{11}^{v} y_{12} \cdots{ }^{v} y_{1 m}, y_{21} y_{22}, \cdots{ }^{v} y_{2 m}, y_{11} v y_{12}, \cdots{ }^{v} y_{n m}\right)
$$

where $v$ is the maximum operator, and $G$ is the optimal vector.

\subsubsection{Calculating the Weight}

We used the gray correlation method to calculate both the connection number and the weight according to that number. The gray correlation coefficient $\delta_{i}=\left(y_{i}, G\right)$ is calculated as

$$
\delta_{i}=\left(y_{i}, G\right)=\frac{\min _{i} \min _{j}\left|y_{i j}-g_{i}\right|+\rho \max _{i} \max _{j}\left|y_{i j}-g_{i}\right|}{\left|y_{i j}-g_{i}\right|+\rho \max _{i} \max _{j}\left|y_{i j}-g_{i}\right|}
$$

where $\delta$ stands for the gray correlation coefficient, $\min _{i} \min _{j}\left|y_{i j}-g_{i}\right|$ represents two levels of minor difference, $\max _{i} \max _{j}\left|y_{i j}-g_{i}\right|$ denotes two levels of great difference, and $\rho$ is the distinguishing coefficient $0<\rho<1, \rho=0.5$.

The weight formula $\left(W_{i}\right)$ is calculated by the equation

$$
W_{i}=\frac{\delta_{i}}{\sum_{i=1}^{n} \delta_{i}}
$$

where $W$ represents the weights of each indicator. 


\subsection{Matter-Element Analysis of Water Resource Security}

Developed by Chinese scholar Cai Wen in the 1980s, the matter-element analysis method can obtain the comprehensive evaluation result by calculating the correlation coefficient between a single index and each standard grade. This can effectively identify the degree of membership between the index and the evaluation grade, as well as avoid omitting some evaluation information within a single index. The main advantages of this method include its use of comprehensive factors without the loss of information and its quantitative, objective expression of results [25,27].

\subsubsection{Matter-Element of Water Resource Security}

In our evaluation of water security for the area (or time) $N$, the one-dimensional matter-element matrix $R=(N, c, x)$ incorporates the feature vector $c$ and value feature vector $x$. If $N$ has $n$ feature vectors with corresponding values $X_{1}, X_{2}, \ldots, X_{n}$, this is termed the $n$-dimensional element of the water security evaluation, and $R$ is the $n$-dimensional model of that evaluation. This relationship is shown by the following equation $[25,27]$ :

$$
R=(N, c, x)\left|\begin{array}{ccc}
N & c_{1} & X_{1} \\
& c_{2} & X_{2} \\
& \vdots & \vdots \\
& c_{n} & X_{n}
\end{array}\right| .
$$

\subsubsection{Determining the Classical and Joint Domains of the Matter-Element Matrix}

In evaluations of water resource security, the classical domain element matrix can be expressed as $R_{o j}=\left(N_{o j}, C_{i}, X_{o}\right)$, where $N_{o j}$ is the $j$ th rating $(j=1,2, \ldots, n)$ and $C_{i}$ represents the $i$ th index. Therefore, in our evaluation, the matter-element matrix of the classical domain can be expressed as $[25,27]$

$$
R_{o j}=\left(N_{o j}, C_{i}, X_{o}\right)\left|\begin{array}{ccc}
N & c_{1} & \left(a_{o j 1}, b_{o j 1}\right) \\
& c_{2} & \left(a_{o j 1}, b_{o j 1}\right) \\
& \vdots & \vdots \\
& c_{n} & \left(a_{o j 1}, b_{o j 1}\right)
\end{array}\right|
$$

where $\left(a_{o j i}, b_{o j i}\right)$ denotes the range of values at level $j$.

Similarly, the matter-element matrix of the joint domain is expressed as $R_{p}=\left(N_{p}, C_{n}, v_{n}\right)$, where $R_{p}$ is the joint domain element and $p$ is the overall rating. Therefore, in our evaluation of water resource security, the formula for the domain element matrix is $[25,27]$

$$
R_{p}=\left(N_{o j}, C_{n}, V_{n}\right)\left|\begin{array}{ccc}
N & c_{1} & \left(a_{p 1}, b_{p 1}\right) \\
& c_{2} & \left(a_{p 2}, b_{p 2}\right) \\
& \vdots & \vdots \\
& c_{n} & \left(a_{p n}, b_{p n}\right)
\end{array}\right|
$$

where $\left(a_{p n}, b_{p n}\right)$ represents the range of the value of the joint domain element.

\subsubsection{Determining the Evaluation Element}

The matter-element of evaluation objects $\left(R_{M}\right)$ is expressed as

$$
R_{M}=(N, c, x)\left|\begin{array}{ccc}
N_{M} & c_{1} & c_{1} \\
& c_{2} & c_{2} \\
& \vdots & \vdots \\
& c_{n} & c_{N}
\end{array}\right|
$$


2.5.4. Determining the Correlation Function and Degree of Correlation

The matter-element of evaluation objects $\left(R_{M}\right)$ is expressed as

$$
X_{o}=[a, b],\left|X_{o}=\right| b-a||
$$

where $X_{o}$ represents the classical domain of the matter-element matrix.

The water safety evaluation index correlation function $K(x)$ is calculated using the formulas

$$
\begin{gathered}
K\left(X_{i}\right)=\left\{\begin{array}{c}
\frac{-p\left(X, X_{o}\right)}{\left|X_{o}\right|} X \in X_{o} \\
\frac{p\left(X, X_{o}\right)}{p\left(X, X_{p}\right)-p\left(X, X_{o}\right)} X \notin X_{o}
\end{array}\right. \\
\left\{\begin{array}{l}
P\left(X, X_{o}\right)=\left|X-0.5\left(a_{o}-b_{o}\right)\right|-0.5\left(b_{o}-a_{o}\right) \\
P\left(X, X_{p}\right)=\left|X-0.5\left(a_{p}-b_{p}\right)\right|-0.5\left(b_{p}-a_{p}\right)
\end{array}\right.
\end{gathered}
$$

where $\left(X, X_{o}\right)$ is the distance between $X$ and the finite interval of the corresponding eigenvector $X_{o}=\left[a_{0}, b_{o}\right] ; p\left(X, X_{p}\right)$ is the distance between $X$ and the finite interval of the eigenvector segment of joint domain $X_{p}=\left[a_{p}, b_{p}\right] ; X, X_{0}$, and $X_{p}$ are the values of the water security evaluation, the range of the value range of the classical domain, and the range of the value of joint domain, respectively $[25,27]$.

\subsubsection{Comprehensive Correlation Degree and Rating}

The synthetic correlation of level $j$ for evaluation objects $N_{M}(M=1,2,3, \ldots, m)$ is expressed as

$$
K_{j}\left(N_{M}\right)=\sum_{i=1}^{n} W_{i} K_{j}\left(X_{i}\right)
$$

where $W_{\mathrm{i}}$ is weight, $K_{j}\left(N_{m}\right)$ is the comprehensive correlation, and $K_{j}\left(X_{i}\right)$ is the degree of association of a single indicator. This treatment determines which class the object belongs to according to the principle of large numbers, such that $K_{j m}=\max \left[K_{j}\left(N_{m}\right)\right]$. When $K<1$, the evaluation object fails to meet the rating requirement and cannot be converted into the rating scale. When $-1<K<0$, the object does not conform to the evaluation requirements, yet has conditions that can be transformed into an evaluation grade, with larger values yielding more straightforward conversions. When $K>0$, the evaluation object conforms to the grade evaluation requirements, with higher values representing greater stability of the object at its corresponding level $[25,27]$.

\subsection{The Evaluation Index System}

The evaluation index system is an area of great interest in the study of water resource security, and the water resource conditions in karst areas are complex [9,30,31]. Therefore, the establishment of a water resource security evaluation index system in karst areas is both compelling and challenging.

\subsubsection{Evaluation Index System Based on DPSIR Modeling of Karst Area Water Security}

DPSIRM provides an indicator framework for the quantitative assessment of water resource security in karst areas, as well as a new research perspective. As the distribution of water resources is regionally variable, evaluation index systems need to accommodate those differences. Accordingly, in our assessment of the Guizhou karst region based on the DPSIRM framework and existing studies, an evaluation index system for water resource security in karst areas was established according to the principles of representativeness, independence, index quantification, and systematisms (Table 1). In addition, subjective indicators, such as the integrity and implementation of water resource protection and management systems and the availability of data on flood control and drought, were scored on a 10-point scale. 


\subsubsection{Classical and Joint Domains of Water Security Evaluation}

According to the principle of extensibility, the state of water resource security can be divided into five levels, $N_{o 1}-N_{o 2}$, corresponding to the classifications (1) "very safe", (2) "generally safe", (3) "barely safe", (4) "unsafe", and (5) "very unsafe", respectively. As an indicator of karst water security, this standard exhibits regional differences due to variations in ecological and environmental vulnerability [25,26] and water pollution, as well as safety indexes and standards issued by local governments and planning initiatives. Due to the fragile ecological environment and low environmental capacity in the karst area, the safety standard may be subject to further adjustment based on expert advice (e.g., partial values may be reduced by 5-50\%) to determine each index range in the classical domain. Values for the classical domain matrix $-R_{o 1}, R_{o 2}, R_{o 3}, R_{o 4}$, and $R_{o 5}$-and the joint domain matrix $R_{P}$ are given below.

\begin{tabular}{|c|c|c|c|c|c|c|c|c|c|c|c|}
\hline & $\mid \begin{array}{cc}N_{o 1} & \text { Very safe } \\
& c_{1}(12000,30000)\end{array}$ & & $\left|\begin{array}{ll}N_{o 2} & \text { Generally safe } \\
& c_{1}(8000,12000)\end{array}\right|$ & & $\mid \begin{array}{lc}N_{o 3} & \text { Barely safe } \\
& c_{1}(5000,8000)\end{array}$ & & $\left|\begin{array}{cc}N_{o 4} & \text { Unsafe } \\
& c_{1}(2000,5000)\end{array}\right|$ & & $\mid \begin{array}{ll}N_{o 5} & \text { Very Unsafe } \\
& c_{1}(0,2000)\end{array}$ & & $\left|\begin{array}{ll}N_{p} & \\
& c_{1}(0,30000)\end{array}\right|$ \\
\hline & $c_{2}(0,400)$ & & $c_{2}(400,800)$ & & $c_{2}(800,2000)$ & & $c_{2}(2000,5000)$ & & $c_{2}(5000,10000)$ & & $c_{2}(0,10000)$ \\
\hline & $c_{3}(0,30)$ & & $c_{3}(30,40)$ & & $c_{3}(40,50)$ & & $c_{3}(50,60)$ & & $c_{3}(60,100)$ & & $c_{3}(0,100)$ \\
\hline & $c_{4}(60,100)$ & & $c_{4}(50,60)$ & & $c_{4}(40,50)$ & & $c_{4}(30,40)$ & & $c_{4}(0,30)$ & & $c_{4}(0,100)$ \\
\hline & $c_{5}(0,10)$ & & $c_{5}(10,15)$ & & $c_{5}(15,20)$ & & $c_{5}(20,30)$ & & $c_{5}(30,100)$ & & $c_{5}(0,100)$ \\
\hline & $c_{6}(0,300)$ & & $c_{6}(300,600)$ & & $c_{6}(600,1000)$ & & $c_{6}(1000,1500)$ & & $c_{6}(1500,2500)$ & & $c_{6}(0,2500)$ \\
\hline & $c_{7}(0,200)$ & & $c_{7}(200,400)$ & & $c_{7}(400,600)$ & & $c_{7}(600,1000)$ & & $c_{7}(1000,2000)$ & & $c_{7}(0,2000)$ \\
\hline & $c_{8}(0,500)$ & & $c_{8}(500,1000)$ & & $c_{8}(1000,1500)$ & & $c_{8}(1500,2000)$ & & $c_{8}(2000,3000)$ & & $c_{8}(0,3000)$ \\
\hline & $c_{9}(0,10)$ & & $c_{9}(10,20)$ & & $c_{9}(20,35)$ & & $c_{9}(35,50)$ & & $c_{9}(50,70)$ & & $c_{9}(0,70)$ \\
\hline & $c_{10}(0,100)$ & & $c_{10}(100,250)$ & & $c_{10}(250,400)$ & & $c_{10}(400,500)$ & & $c_{10}(500,700)$ & & $c_{10}(0,700)$ \\
\hline & $c_{11}(3000,4000)$ & & $c_{11}(2500,3000)$ & & $c_{11}(1500,2500)$ & & $c_{11}(500,1500)$ & & $c_{11}(0,500)$ & & $c_{11}(0,4000)$ \\
\hline$R_{o 1}=$ & $c_{12}(200,300)$ & $R_{02}=$ & $c_{12}(150,200)$ & $R_{03}=$ & $c_{12}(100,150)$ & $R_{04}=$ & $c_{12}(50,100)$ & $R_{05}=$ & $c_{12}(0,50)$ & $R_{p}=$ & $c_{12}(0,300)$ \\
\hline & $c_{13}(0,5)$ & & $c_{13}(5,10)$ & & $c_{13}(10,20)$ & & $c_{13}(20,25)$ & & $c_{13}(25,100)$ & & $c_{13}(0,100)$ \\
\hline & $c_{14}(40,100)$ & & $c_{14}(30,40)$ & & $c_{14}(20,30)$ & & $c_{14}(10,20)$ & & $c_{14}(0,10)$ & & $c_{14}(0,100)$ \\
\hline & $c_{15}(90,100)$ & & $c_{15}(80,90)$ & & $c_{15}(70,80)$ & & $c_{15}(60,70)$ & & $c_{15}(0,60)$ & & $c_{15}(0,100)$ \\
\hline & $c_{16}(0,1)$ & & $c_{16}(1,2.5)$ & & $c_{16}(2.5,4)$ & & $c_{16}(4,5.5)$ & & $c_{16}(5.5,10)$ & & $c_{16}(0,10)$ \\
\hline & $c_{17}(0,200)$ & & $c_{17}(200,1000)$ & & $c_{17}(1000,2500)$ & & $c_{17}(2500,5000)$ & & $c_{17}(5000,7000)$ & & $c_{17}(0,7000)$ \\
\hline & $c_{18}(80,100)$ & & $c_{18}(70,80)$ & & $c_{18}(60,70)$ & & $c_{18}(45,60)$ & & $c_{18}(0,45)$ & & $c_{18}(0,100)$ \\
\hline & $c_{19}(90,100)$ & & $c_{19}(80,90)$ & & $c_{19}(70,80)$ & & $c_{19}(60,70)$ & & $c_{19}(0,60)$ & & $c_{19}(0,100)$ \\
\hline & $c_{20}(0,5)$ & & $c_{20}(5,15)$ & & $c_{20}(15,30)$ & & $c_{20}(30,45)$ & & $c_{20}(45,100)$ & & $c_{20}(0,100)$ \\
\hline & $c_{21}(1.5,3)$ & & $c_{21}(1,1.5)$ & & $c_{21}(1,0.6)$ & & $c_{21}(0.3,0.6)$ & & $c_{21}(0,0.3)$ & & $c_{21}(0,3)$ \\
\hline & $c_{22}(9,10)$ & & $c_{22}(7,9)$ & & $c_{22}(6,7)$ & & $c_{22}(5,6)$ & & $c_{22}(0,5)$ & & $c_{22}(0,10)$ \\
\hline & $c_{23}(9,10)$ & & $c_{23}(7,9)$ & & $c_{23}(6,7)$ & & $c_{23}(5,6)$ & & $c_{23}(0,5)$ & & $c_{23}(0,10)$ \\
\hline & $c_{24}(9,10)$ & & $c_{24}(7,9)$ & & $c_{24}(6,7)$ & & $c_{24}(5,6)$ & & $c_{24}(0,5)$ & & $c_{24}(0,10)$ \\
\hline
\end{tabular}

\section{Results and Discussion}

According to the research methods in the second part of this paper, the following results and conclusions are drawn.

We used the gray correlation method to calculate the weight of each rating index listed in Table 1. Using Equations (11) and (12), we then incorporated the matter-element $R_{2005}-R_{2012}$ into the matter-element analysis model to evaluate index correlation degrees, factor layer correlation degrees, and comprehensive correlation degrees for the Guizhou region (Tables 2-4). For 2005, for example, the correlation degrees $\left(k_{j}\left(x_{1}\right)\right)$ of the five corresponding grades are $N_{o 1}=-0.021$, $N_{o 2}=0.013, N_{o 3}=0.001, N_{o 4}=0.000$, and $N_{o 5}=-0.014$. We can conclude, therefore, that the natural growth rate of the population is $N_{\mathrm{o} 2}$, which is classed as "generally safe". Other indicators give similar results (Table 2). For instance, the correlation degrees $\left(K_{j}\left(N_{2005}\right)\right)$ of the five corresponding grades are $N_{o 1}=-0.326, N_{o 2}=0.290, N_{o 3}=-0.155, N_{o 4}=-0.230$, and $N_{o 5}=-0.359$. Thus, according to the judging criteria, water resource security in Guizhou province for 2005 was Grade 2, or "generally safe". Evaluation factor levels and security levels for all years are given in Tables 3 and 4, respectively. 
Table 2. Correlation degree and evaluation results of the water resource security evaluation index.

\begin{tabular}{|c|c|c|c|c|c|c|c|c|c|c|c|c|c|}
\hline \multirow{2}{*}{$\begin{array}{l}\text { Correlation } \\
\text { Degree }\end{array}$} & \multicolumn{5}{|c|}{2005} & 2005 & 2006 & 2007 & 2008 & 2009 & 2010 & 2011 & 2012 \\
\hline & $N_{o 1}$ & $N_{o 2}$ & $N_{o 3}$ & $N_{o 4}$ & $N_{o 5}$ & \multicolumn{8}{|c|}{ Grade } \\
\hline$k_{j}\left(x_{1}\right)$ & -0.021 & 0.013 & 0.001 & 0.000 & -0.014 & 2 & 3 & 3 & 2 & 2 & 1 & 1 & 1 \\
\hline$k_{j}\left(x_{2}\right)$ & 0.020 & 0.020 & -0.032 & -0.038 & -0.041 & 2 & 1 & 1 & 1 & 1 & 1 & 1 & 1 \\
\hline$k_{j}\left(x_{3}\right)$ & 0.005 & 0.005 & 0.015 & -0.020 & -0.024 & 1 & 3 & 3 & 1 & 1 & 2 & 3 & 3 \\
\hline$k_{j}\left(x_{4}\right)$ & -0.013 & 0.008 & 0.002 & -0.001 & -0.008 & 2 & 3 & 2 & 2 & 1 & 1 & 1 & 1 \\
\hline$k_{j}\left(x_{5}\right)$ & -0.011 & 0.005 & 0.015 & -0.004 & -0.015 & 3 & 3 & 3 & 3 & 2 & 2 & 3 & 3 \\
\hline$k_{j}\left(x_{6}\right)$ & -0.012 & 0.012 & -0.006 & -0.020 & -0.027 & 2 & 2 & 2 & 2 & 3 & 3 & 3 & 3 \\
\hline$k_{j}\left(x_{7}\right)$ & -0.012 & 0.004 & -0.002 & -0.013 & -0.022 & 2 & 2 & 2 & 2 & 2 & 2 & 2 & 1 \\
\hline$k_{j}\left(x_{8}\right)$ & -0.017 & 0.011 & 0.000 & 0.001 & -0.010 & 2 & 4 & 3 & 3 & 2 & 2 & 2 & 2 \\
\hline$k_{j}\left(x_{9}\right)$ & -0.016 & 0.002 & 0.003 & -0.019 & -0.027 & 3 & 2 & 2 & 1 & 2 & 2 & 2 & 2 \\
\hline$k_{j}\left(x_{0}\right)$ & -0.024 & 0.018 & -0.006 & 0.017 & -0.008 & 2 & 4 & 4 & 4 & 4 & 4 & 5 & 5 \\
\hline$k_{j}\left(x_{11}\right)$ & -0.012 & 0.006 & 0.014 & -0.009 & -0.018 & 3 & 3 & 2 & 2 & 1 & 2 & 3 & 3 \\
\hline$k_{j}\left(x_{12}\right)$ & -0.034 & 0.031 & -0.023 & 0.000 & 0.000 & 2 & 5 & 4 & 4 & 4 & 4 & 5 & 4 \\
\hline$k_{j}\left(x_{13}\right)$ & -0.019 & 0.015 & -0.001 & 0.004 & -0.008 & 2 & 4 & 3 & 3 & 3 & 3 & 3 & 3 \\
\hline$k_{j}\left(x_{14}\right)$ & -0.005 & 0.020 & -0.006 & -0.014 & -0.019 & 2 & 2 & 2 & 2 & 2 & 1 & 1 & 1 \\
\hline$k_{i}\left(x_{15}\right)$ & -0.018 & 0.013 & -0.006 & 0.015 & -0.004 & 4 & 5 & 4 & 4 & 4 & 3 & 3 & 4 \\
\hline$k_{j}\left(x_{16}\right)$ & -0.016 & 0.026 & -0.017 & -0.031 & -0.037 & 2 & 3 & 2 & 5 & 1 & 3 & 4 & 1 \\
\hline$k_{j}\left(x_{17}\right)$ & -0.009 & 0.005 & -0.023 & -0.030 & -0.032 & 2 & 2 & 2 & 2 & 2 & 2 & 1 & 1 \\
\hline$k_{j}\left(x_{18}\right)$ & -0.028 & 0.027 & -0.025 & -0.020 & 0.018 & 2 & 5 & 5 & 5 & 5 & 3 & 1 & 1 \\
\hline$k_{j}\left(x_{19}\right)$ & -0.016 & 0.010 & -0.003 & 0.009 & -0.007 & 2 & 3 & 3 & 3 & 3 & 3 & 2 & 2 \\
\hline$k_{j}\left(x_{20}\right)$ & -0.018 & 0.017 & -0.011 & -0.030 & -0.036 & 2 & 2 & 2 & 2 & 2 & 2 & 3 & 2 \\
\hline$k_{j}\left(x_{21}\right)$ & 0.006 & 0.006 & -0.015 & -0.020 & -0.023 & 1 & 1 & 1 & 1 & 1 & 1 & 1 & 2 \\
\hline$k_{j}\left(x_{22}\right)$ & -0.022 & 0.017 & -0.013 & -0.007 & 0.007 & 2 & 5 & 4 & 4 & 4 & 3 & 3 & 3 \\
\hline$k_{j}\left(x_{23}\right)$ & -0.017 & 0.011 & -0.006 & 0.004 & -0.001 & 2 & 4 & 4 & 3 & 3 & 2 & 2 & 2 \\
\hline$k_{j}\left(x_{24}\right)$ & -0.017 & -0.011 & -0.006 & 0.000 & 0.000 & 4 & 4 & 4 & 3 & 3 & 3 & 3 & 2 \\
\hline
\end{tabular}

Table 3. Correlation degrees of DPSIRM factor layers and evaluation results.

\begin{tabular}{|c|c|c|c|c|c|c|c|c|}
\hline Years & $\begin{array}{l}\text { Comprehensive } \\
\text { Correlative Degree }\end{array}$ & $N_{o 1}$ & $N_{o 2}$ & $N_{o 3}$ & $N_{o 4}$ & $N_{o 5}$ & $\begin{array}{c}\text { Gray Matter-Element } \\
\text { Method }\end{array}$ & $\begin{array}{l}\text { Gray Set Pair } \\
\text { Method }\end{array}$ \\
\hline \multirow{6}{*}{2005} & $K_{j}\left(N_{2005}, D\right)$ & -0.102 & 0.254 & 0.006 & -0.316 & -0.510 & Generally safe & Barely safe \\
\hline & $K_{j}\left(N_{2005}, P\right)$ & -0.387 & 0.228 & -0.058 & -0.163 & -0.457 & Generally safe & Barely safe \\
\hline & $K_{j}\left(N_{2005}, S\right)$ & -0.511 & 0.405 & -0.074 & -0.044 & -0.202 & Generally safe & Unsafe \\
\hline & $K_{j}\left(N_{2005}, I\right)$ & -0.272 & 0.363 & -0.311 & -0.361 & -0.538 & Generally safe & Generally safe \\
\hline & $K_{j}\left(N_{2005}, R\right)$ & -0.496 & 0.434 & -0.310 & -0.319 & -0.182 & Generally safe & Unsafe \\
\hline & $K_{j}\left(N_{2005}, M\right)$ & -0.314 & 0.137 & -0.250 & -0.141 & -0.100 & Generally safe & Very unsafe \\
\hline \multirow{6}{*}{2006} & $K_{j}\left(N_{2006}, D\right)$ & -0.073 & -0.198 & 0.098 & -0.370 & -0.533 & Barely safe & Barely safe \\
\hline & $K_{j}\left(N_{2006}, P\right)$ & -0.362 & 0.101 & -0.173 & -0.214 & -0.488 & Generally safe & Generally safe \\
\hline & $K_{j}\left(N_{2006}, S\right)$ & -0.521 & -0.419 & -0.069 & -0.065 & -0.168 & Unsafe & Unsafe \\
\hline & $K_{j}\left(N_{2006}, I\right)$ & -0.264 & -0.068 & -0.231 & -0.391 & -0.465 & Generally safe & Generally safe \\
\hline & $K_{j}\left(N_{2006}, R\right)$ & -0.494 & -0.196 & -0.214 & -0.402 & -0.208 & Generally safe & Barely safe \\
\hline & $K_{j}\left(N_{2006}, M\right)$ & -0.340 & -0.218 & -0.187 & 0.106 & -0.134 & Unsafe & Unsafe \\
\hline \multirow{6}{*}{2007} & $K_{j}\left(N_{2007}, D\right)$ & -0.036 & -0.121 & 0.014 & -0.392 & -0.533 & Barely safe & Generally safe \\
\hline & $K_{j}\left(N_{2007}, P\right)$ & -0.315 & 0.041 & -0.167 & -0.327 & -0.541 & Generally safe & Generally safe \\
\hline & $K_{j}\left(N_{2007}, S\right)$ & -0.459 & -0.239 & -0.131 & -0.085 & -0.317 & Unsafe & Unsafe \\
\hline & $K_{j}\left(N_{2007}, I\right)$ & -0.228 & 0.057 & -0.356 & -0.360 & -0.567 & Generally safe & Very safe \\
\hline & $K_{j}\left(N_{2007}, R\right)$ & -0.442 & -0.102 & -0.242 & -0.384 & -0.270 & Generally safe & Barely safe \\
\hline & $K_{j}\left(N_{2007}, M\right)$ & -0.267 & -0.236 & -0.178 & 0.014 & -0.219 & Unsafe & Barely safe \\
\hline \multirow{6}{*}{2008} & $K_{j}\left(N_{2008}, D\right)$ & 0.004 & 0.033 & -0.033 & -0.424 & -0.553 & Generally safe & Generally safe \\
\hline & $K_{j}\left(N_{2008}, P\right)$ & -0.240 & -0.021 & -0.302 & -0.399 & -0.580 & Generally safe & Generally safe \\
\hline & $K_{j}\left(N_{2008}, S\right)$ & -0.435 & -0.222 & -0.151 & -0.113 & -0.338 & Unsafe & Unsafe \\
\hline & $K_{j}\left(N_{2008}, I\right)$ & -0.471 & -0.334 & -0.514 & -0.520 & -0.337 & Generally safe & Barely safe \\
\hline & $K_{j}\left(N_{2008}, R\right)$ & -0.434 & -0.093 & -0.237 & -0.367 & -0.284 & Generally safe & Barely safe \\
\hline & $K_{j}\left(N_{2008}, M\right)$ & -0.305 & -0.141 & 0.041 & -0.079 & -0.273 & Barely safe & Barely safe \\
\hline \multirow{6}{*}{2009} & $K_{j}\left(N_{2009}, D\right)$ & 0.125 & -0.061 & -0.247 & -0.523 & -0.625 & Very safe & Very safe \\
\hline & $K_{j}\left(N_{2009}, P\right)$ & -0.329 & -0.065 & -0.157 & -0.331 & -0.496 & Generally safe & Generally safe \\
\hline & $K_{j}\left(N_{2009}, S\right)$ & -0.340 & -0.412 & -0.245 & -0.229 & -0.340 & Unsafe & Barely safe \\
\hline & $K_{j}\left(N_{2009}, I\right)$ & -0.109 & -0.073 & -0.428 & -0.430 & -0.605 & Generally safe & Very safe \\
\hline & $K_{j}\left(N_{2009}, R\right)$ & -0.405 & -0.057 & -0.161 & -0.262 & -0.341 & Generally safe & Barely safe \\
\hline & $K_{j}\left(N_{2009}, M\right)$ & -0.259 & -0.194 & -0.007 & -0.065 & -0.300 & Barely safe & Barely safe \\
\hline \multirow{6}{*}{2010} & $K_{j}\left(N_{2010}, D\right)$ & 0.178 & -0.142 & -0.280 & -0.547 & -0.642 & Very safe & Very safe \\
\hline & $K_{j}\left(N_{2010}, P\right)$ & -0.348 & 0.013 & -0.129 & -0.343 & -0.506 & Generally safe & Generally safe \\
\hline & $K_{j}\left(N_{2010}, S\right)$ & -0.474 & -0.319 & -0.081 & -0.141 & -1.343 & Barely safe & Barely safe \\
\hline & $K_{j}\left(N_{2010}, I\right)$ & -0.286 & -0.098 & -0.128 & -0.285 & -0.460 & Generally safe & Barely safe \\
\hline & $K_{j}\left(N_{2010}, R\right)$ & -0.330 & 0.098 & 0.081 & -0.367 & -0.542 & Barely safe & Barely safe \\
\hline & $K_{j}\left(N_{2010}, M\right)$ & -0.232 & -0.139 & -0.021 & -0.240 & -0.381 & Barely safe & Barely safe \\
\hline
\end{tabular}


Table 3. Cont.

\begin{tabular}{|c|c|c|c|c|c|c|c|c|}
\hline Years & $\begin{array}{c}\text { Comprehensive } \\
\text { Correlative Degree }\end{array}$ & $N_{o 1}$ & $N_{o 2}$ & $N_{o 3}$ & $N_{o 4}$ & $N_{o 5}$ & $\begin{array}{c}\text { Gray Matter-Element } \\
\text { Method }\end{array}$ & $\begin{array}{c}\text { Gray Set Pair } \\
\text { Method }\end{array}$ \\
\hline \multirow{6}{*}{2011} & $K_{j}\left(N_{2011}, D\right)$ & 0.129 & -0.127 & -0.067 & -0.474 & -0.589 & Very safe & Very safe \\
\hline & $K_{j}\left(N_{2011}, P\right)$ & -0.289 & -0.068 & -0.290 & -0.474 & -0.515 & Generally safe & Generally safe \\
\hline & $K_{j}\left(N_{2011}, S\right)$ & -0.555 & -0.457 & -0.041 & -0.195 & -0.129 & Barely safe & Unsafe \\
\hline & $K_{j}\left(N_{2011}, I\right)$ & -0.157 & -0.214 & -0.196 & -0.220 & -0.448 & Very safe & Barely safe \\
\hline & $K_{j}\left(N_{2011}, R\right)$ & -0.219 & -0.025 & -0.130 & -0.465 & -0.617 & Generally safe & Generally safe \\
\hline & $K_{j}\left(N_{2011}, M\right)$ & -0.229 & -0.120 & 0.034 & -0.260 & -0.397 & Barely safe & Barely safe \\
\hline \multirow{6}{*}{2012} & $K_{j}\left(N_{2012}, D\right)$ & 0.166 & -0.216 & -0.152 & -0.483 & -0.602 & Very safe & Very safe \\
\hline & $K_{j}\left(N_{2012}, P\right)$ & -0.189 & -0.173 & -0.402 & -0.547 & -0.531 & Generally safe & Very safe \\
\hline & $K_{j}\left(N_{2012}, S\right)$ & -0.446 & -0.268 & -0.117 & -0.165 & -1.489 & Barely safe & Barely safe \\
\hline & $K_{j}\left(N_{2012}, I\right)$ & -0.068 & -0.084 & -0.423 & -0.509 & -0.625 & Very safe & Very safe \\
\hline & $K_{j}\left(N_{2012}, R\right)$ & -0.134 & 0.144 & -0.327 & -0.576 & -0.694 & Generally safe & Generally safe \\
\hline & $K_{j}\left(N_{2012}, M\right)$ & -0.308 & 0.095 & 0.016 & -0.286 & -0.415 & Barely safe & Generally safe \\
\hline
\end{tabular}

Table 4. Comprehensive correlative degrees and results for the water resource security evaluation index.

\begin{tabular}{ccccccccc}
\hline Years & $\begin{array}{c}\text { Comprehensive } \\
\text { Correlative Degree }\end{array}$ & $N_{\boldsymbol{o 1}}$ & $\boldsymbol{N}_{\boldsymbol{o} \mathbf{2}}$ & $\boldsymbol{N}_{\boldsymbol{o 3}}$ & $\boldsymbol{N}_{\boldsymbol{o 4}}$ & $\boldsymbol{N}_{\boldsymbol{o 5}}$ & $\begin{array}{c}\text { Gray Matter-Element } \\
\text { Method }\end{array}$ & $\begin{array}{c}\text { Gray Set Pair } \\
\text { Method }\end{array}$ \\
\hline 2005 & $K_{j}\left(N_{2005}\right)$ & -0.326 & 0.290 & -0.155 & -0.230 & -0.359 & Generally safe & Barely safe \\
2006 & $K_{j}\left(N_{2006}\right)$ & -0.318 & -0.144 & -0.123 & -0.229 & -0.361 & Barely safe & Barely safe \\
2007 & $K_{j}\left(N_{2007}\right)$ & -0.269 & -0.087 & -0.172 & -0.266 & -0.431 & Generally safe & Generally safe \\
2008 & $K_{j}\left(N_{2008}\right)$ & -0.293 & -0.123 & -0.205 & -0.333 & -0.413 & Generally safe & Generally safe \\
2009 & $K_{j}\left(N_{2009}\right)$ & -0.197 & -0.130 & -0.213 & -0.323 & -0.472 & Generally safe & Generally safe \\
2010 & $K_{j}\left(N_{2010}\right)$ & -0.227 & -0.096 & -0.110 & -0.333 & -0.616 & Generally safe & Generally safe \\
2011 & $K_{j}\left(N_{2011}\right)$ & -0.197 & -0.161 & -0.124 & -0.355 & -0.460 & Barely safe & Generally safe \\
2012 & $K_{j}\left(N_{2012}\right)$ & -0.142 & -0.096 & -0.242 & -0.439 & -0.686 & Generally safe & Generally safe \\
\hline
\end{tabular}

\subsection{Results of Correlation Degree of Indexes and Factors Influencing}

According to Equation (3), the matrix $R$ values are as follows:

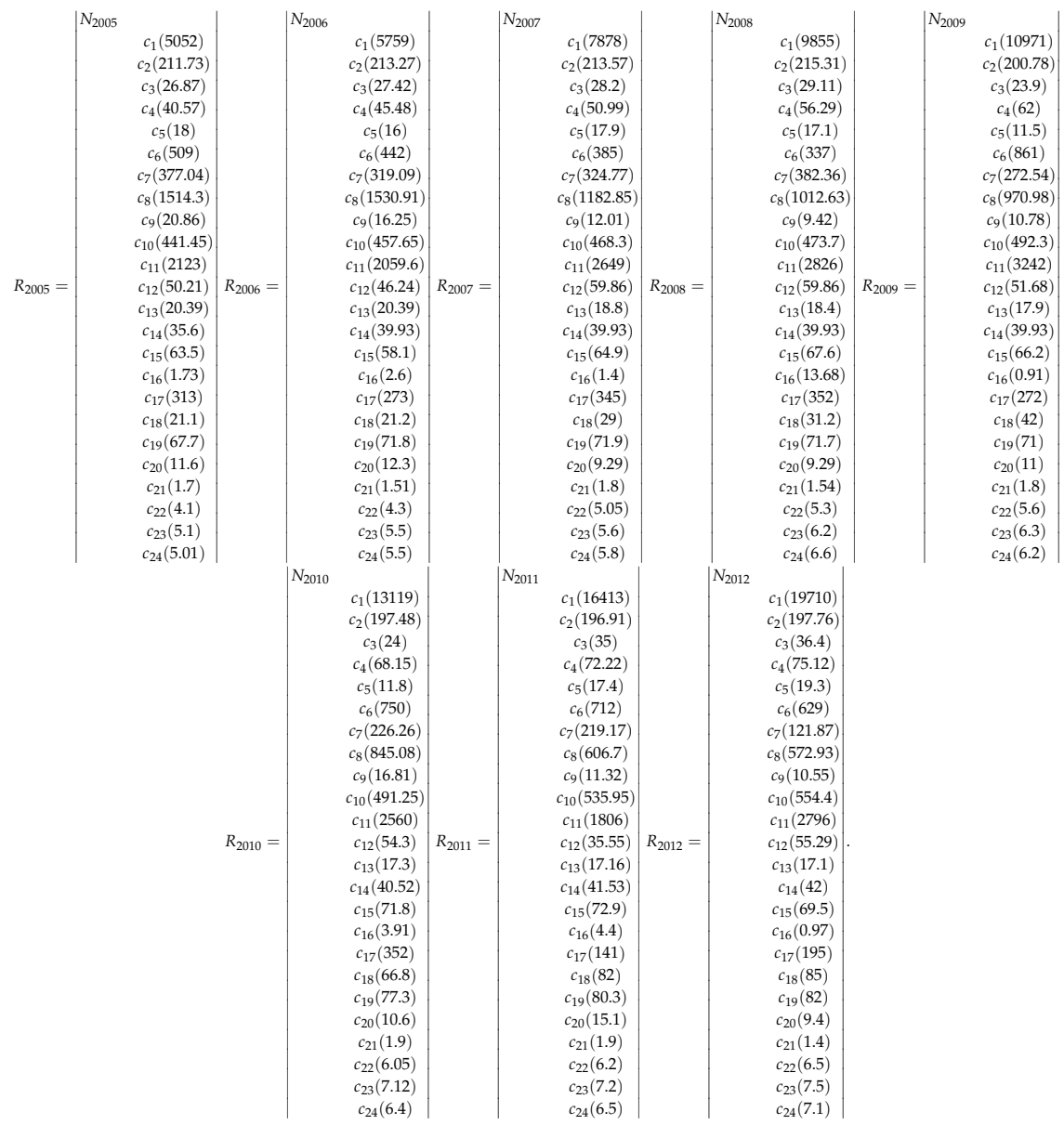


As can be seen from Table 1 (weight $\geq 0.042$ ), the factors influencing water resource security are population density, urbanization rate, discharge of waste water per unit of industrial output, amount of fertilizer used per unit of cultivated area, water resources per unit area, rate of rocky desertification, forest coverage, river water quality index rate, drought and drought damage as a share of GDP, water resource development rate, and environmental protection investment as a percentage of GDP. The greater the absolute value of weight, the greater influence the factor has on water resource security in the karst area. Drought and drought damage as a share of GDP (0.059) reflects the impact of natural disasters. Forest coverage (0.046) and water resources per unit area (0.046) come from the ecological and environmental systems. Discharge of waste water per unit of industrial output (0.045) and rate of rocky desertification (0.045) reflect the disturbance of economic development and human activities. It is evident that the influence of the droughts caused by climate change is much greater than that of the ecological and environmental systems, while the disturbance of economic development and human activities is between the two.

Based on the data in Table 2, the factors of the amount of fertilizer used per unit of cultivated area, river water quality index rate, sewage treatment rate, integrity of the water protection, and management system played a negative role in water security in karst areas. The amount of fertilizer used per unit of cultivated area reached $554.4 \mathrm{~kg}$ in 2012. The sewage treatment rate was only $66.8 \%$ in 2010 and increased to $85 \%$ in 2012 . It is evident that rapid economic development, backward infrastructure, lack of management measures, and non-point agricultural pollution put great pressures on water resources security in karst areas.

\subsection{Results of Water Resource Security Evaluation of DPSIRM Factor Layers}

According to the factor (DPSIRM) differentiation information given in Table 3, the water security level for Guizhou province remained stable between 2005 and 2012. Although the pressure safety level had not changed, $K_{j}\left(N_{2008}, D\right)=-0.021, K_{j}\left(N_{2009}, D\right)=-0.065, K_{j}\left(N_{2011}, D\right)=-0.068$, and $K_{j}\left(N_{2012}, D\right)$ $=-0.173$, meaning that all were $<0$ and thus exhibited a downward trend. In the short term, the driving force of security was generally better, with the years 2009-2012 classed as "very safe". The states of security were classed as "generally safe" in 2005, whereas the period of 2006-2009 was "unsafe" and 2010-2012 was classed as "barely safe" due to the impact of drought and floods. Management of security was classed as "unsafe" in both 2006 and 2007. The period of 2008-2012 was classed as "barely safe". In 2006, the average precipitation of Guizhou province was $1015.1 \mathrm{~mm}$, and the total amount of water resources was 81.46 billion $\mathrm{m}^{3}$, which was $23.3 \%$ less than the normal year. In 2011, the average precipitation of the province was $820.6 \mathrm{~mm}$, and the total amount of water resources was 62.635 billion $\mathrm{m}^{3}$, which was $41.0 \%$ less than the normal year. As a result, in 2006 and 2011, water resources per capita and per unit area were $2059.6 \mathrm{~m}^{3} /$ person, $1806 \mathrm{~m}^{3} /$ person, $46.241 \mathrm{~m}^{3} / \mathrm{km}^{2}$, and $35.551 \mathrm{~m}^{3} / \mathrm{km}^{2}$, respectively, which was far lower than that of the normal year. This made $K_{j}\left(N_{2006}\right.$, $S)$ and $K_{j}\left(N_{2011}, S\right)$ to be classified as "unsafe" and "barely safe", respectively. It can be seen that extreme droughts caused by climate change have a great impact on "water security states" in karst areas. From 2006 to 2009, the rate of rocky desertification reached $20.39 \%, 18.8 \%, 18.4 \%$, and $17.9 \%$, respectively. Therefore, $K_{j}\left(N_{2006}, S\right)-K_{j}\left(N_{2009}, S\right)$ belong to the "unsafe" classification, respectively. The environmental degradation of karst region has a great impact on the water resource security states. In addition, in 2005, although the rate of rocky desertification was as high as $20.39 \%$, the province's average annual rainfall was $1129.7 \mathrm{~mm}$, increasing $9.0 \%$ from the previous year. $K_{j}\left(N_{2005}, S\right)$ increased to be classified as "generally safe". It is evident that, in the current situation, the impact of climate change on water resource security is far greater than environmental degradation.

In 2005 and 2012, the per capita GDP in Guizhou was 5052 and 19,710 yuan/person, respectively, far lower than the national per capita GDP in 2012 (RMB 40,007 yuan/person). In 2005 and 2012, the urbanization rate was $26.87 \%$ and $36.4 \%$, respectively, far lower than the national average of $52.57 \%$. However, between 2015 and 2016, the GDP of Guizhou province increased by 10.5\%, exceeding the national growth rate by $3.8 \%$. Although Guizhou province is an economically backward region, 
its economy has been developing rapidly in recent years. Therefore, economic and social development has limited impacts on water security in the short term, but the pressure is increasing year by year. Both $K_{j}\left(N_{2006}, M\right)$ and $K_{j}\left(N_{2007}, M\right)$ belong to the "unsafe" classification, and values from $K_{j}\left(N_{2008}\right.$, $M)$ to $K_{j}\left(N_{2012}, M\right)$ belong to "barely safe". Current water resource management in karst areas are constraints on water resource security, and there was a lack of management measures for water security in karst areas currently being met.

\subsection{Results of Water Resource Security Comprehensive Evaluation in the Karst Area}

Overall, the data presented in Table 4 showed that water security in Guizhou province was classed as "generally safe" in 2005, "barely safe" in 2006 and 2011 (when the region experienced drought), and "safe" during the remaining years evaluated. For the period of 2006-2012, the degrees of relevance to the security level were less than 0 . For example, the 2006 correlation coefficients were as follows: $0>K_{j}\left(N_{2006}, N_{o 1}\right)=-0.318>K_{j}\left(N_{2006}, N_{o 2}\right)=-0.144>K_{j}\left(N_{2006}, N_{o 3}\right)=-0.123>K_{j}\left(N_{2006}, N_{o 4}\right)=$ $-0.229>K_{j}\left(N_{2006}, N_{05}\right)=-0.361$. This finding showed that, although water resource security was relatively high between 2005 and 2012, it was also highly unstable. Individually, the years 2007, 2008, 2009, 2010, and 2012 were graded as "generally safe". Nonetheless, their respective correlation values are small and $<0$, indicating that none are fully compliant with the $N_{O 2}$ standard. The state of water resource security in the karst area of Guizhou province was not uniformly positive. Going forward, it will be necessary to reduce nonpoint-source agricultural pollution, strengthen water resource management, control urbanization rationally, develop the requisite sewage treatment infrastructure, and increase water conservancy throughout the karst area. Natural disasters such as drought had a greater impact on water security in karst areas relative to non-karst areas [32]. $K_{j}\left(N_{2006}\right)$ and $K_{j}\left(N_{2011}\right)$ both belonged to the "barely safe" classification. It can be seen that extreme droughts caused by climate change played a decisive role in the overall water security in karst areas compared with economic, social, environmental, and resource management factors. Therefore, the next step is to strengthen the construction of water conservancy infrastructure in the karst region of Guizhou and increase the ability to resist drought and disaster in risk resistance. These are important and crucial measures to enhance water resource security in the karst region.

\section{Discussion}

(1) It has been found that water resource security in Guizhou was at a moderate warning level from 2005 to 2009 and a barely safe level from 2010 to 2014 (Liu et al., 2018), shown in Table 5. Results of this study showed that it was at "barely safe" in 2006 and 2011 and at "generally safe" in other years. The two results confirmed each other, which showed that the water resource security of Guizhou province was at the edge of critical security. Results of this study confirmed that the water resource security situation was serious.

Table 5. Research results.

\begin{tabular}{ccc}
\hline Years & Gray Matter-Element Method & Liu et al., 2018 \\
\hline 2005 & Generally safe & Moderate Warning \\
2006 & Barely safe & Moderate Warning \\
2007 & Generally safe & Moderate Warning \\
2008 & Generally safe & Moderate Warning \\
2009 & Generally safe & Moderate Warning \\
2010 & Generally safe & Barely safe \\
2011 & Barely safe & Barely safe \\
2012 & Generally safe & Barely safe \\
\hline
\end{tabular}

Liu et al. (2018) found that the influence of the water environment and economic subsystems was much greater than that of the ecological and human subsystems, while the social subsystem had a level of influence between the two [33]. Results of this study confirmed that the influence of the 
droughts caused by climate change was much greater than that of the ecological and environmental systems, while the disturbance of economic development and human activities had a level of influence between the two. The difference was that Liu et al. did not consider the impact of drought disasters on water security in karst areas. The probability of winter and spring drought in the southwest region (including Guizhou province) was very high, with an average of once every three years, and the severe region could last more than 150 days [33]. Drought disaster is an inevitable and important factor influencing future water resource security in karst areas in the future. In addition to the factors found above, this study also found that water resource management in karst areas was crucial to water resource security.

(2) The same data was processed according to the method outlined in [26] (gray set pair analysis; detailed calculation process is discussed therein), calculation results were shown in Tables 3 and 4 to compare with the research methods of this article. The results obtained by the two methods are slightly different. The reason for this was that the two methods differed in their principles for determining rank. The gray matter-element method adopted the principle of maximum membership, while gray set pair analysis adopted the principle that degree of connection accumulation was greater than 0.5 for the first time. The calculation results of the two methods were "generally safe" and "barely safe" classifications for 2005 and "barely safe" and "generally safe" classifications for 2011, respectively. However, these classifications belonged to adjacent grades. The same was true for other years. Thus, the gray matter-element method is appropriate for evaluating water resource safety. The gray matter-element method is proven to be suitable for evaluating water resource security.

\section{Conclusions}

(1) Using the DPSIR conceptual framework, we constructed a model for evaluating water resource security in karst areas, which we then applied to Guizhou province for the period of 2005-2012. The model incorporates the gray correlation method and matter-element analysis, along with regional data on existing water and land resources and ecosystem health, water resource characteristics in karstic landscapes, and contemporary data on urban construction standards in China relative to global standards. Our results show that Guizhou water resources corresponded to the "generally safe" grade in 2005, to the "barely safe" grade in 2006 and 2011, and again to the "generally safe" grade for the remaining years. The occurrence of drought in both 2006 and 2011 demonstrates that these events have a large impact on karst water resources. From 2005 to 2012, the security of water resources in the Guizhou karst was good yet unstable and, going forward, will continue to face considerable challenges, including drought, agricultural nonpoint-source pollution, rapid urbanization, and an insufficient sewage treatment infrastructure.

(2) Empirical research on the security of karst water resources showed that the internal mechanism of the DPSIRM framework successfully accounts for interactions among various factors, such as climatic, environmental, social, and economic influences. Additionally, it found that water resource management in karst areas was crucial to water resource security. The DPSIRM model reflected the role of water resource management in resource evaluation. The DPSIRM framework highlights the core role of humans in the water resource security system, That is, people can realize the supervision and regulation of water resource security through management. However, the boundary and degree of its role are difficult to be accurately defined in the evaluation of water resource security, which requires further research and improvement.

(3) Through comparison with gray set pair analysis, we showed that the two methods gave consistent results. Further, when compared with the traditional multi-index comprehensive evaluation, the matter-element analysis method not only revealed the differentiation rule between single factor indexes but also showed the relationship between the comprehensive safety level and the intermediate transformation process. The gray correlation method was based on objective and subjective corrections and was more reasonable. Therefore, the gray matter-element method is 
appropriate for evaluating water resource safety, which presents a novel approach for assessing the water resource security issues within (karst) land zones suffering from drought.

(4) Water resources are the principal factor limiting economic and social growth and environmental viability in karst regions. Because the safety evaluation index system is diverse, there is no uniform standard and evaluation methods are numerous. Here, we have presented a DPSIRM-based method that employs the gray correlation method and matter-element analysis to evaluate the security of water resources in karst areas. Not only are our results in accord with the model situation, the method has certain feasibility. Moreover, in addition, the case selected in this study is a typical karst distribution area, which indicates that this research method has certain applicability in the karst area. Due to the limitations of the data time series obtained, our overarching objective was to explore and verify the quantitative evaluation index systems and suitable methods of water security in karst areas. Thus, prediction was not involved and needs to be explored in the future.

Author Contributions: The study was designed by D.S., F.Z., and J.W. The data from yearbooks and professional websites were retrieved by F.Z. and H.H., D.S. and F.Z. wrote the manuscript. W.S. provided important ideas and suggestions.

Funding: This research was funded by the National Science and Technology project of the "13th Five-Year Plan" [2016YFC0400708], the Guizhou Province Science and Technology Support Program [QKH2016-2845], the Guizhou Provincial Science and Technology Plan Sub-Special Project[QKH-J-2015-2001], and the Guizhou Province Science and Technology Fund [QKH-J.2015-2121].

Conflicts of Interest: The authors declare no conflict of interest.

\section{References}

1. Christensen, N.S.; Wood, A.W.; Voisin, N.; Lettenmaier, D.P.; Palmer, R.N. The effects of climate change on the hydrology and water resources of the Colorado River basin. Clim. Chang. 2004, 62, 337-363. [CrossRef]

2. Wang, W.; Tang, D.; Pilgrim, M.; Liu, J. Water Resources Compound Systems: A Macro Approach to Analysing Water Resource Issues under Changing Situations. Water 2015, 8, 2-12. [CrossRef]

3. Jackson, R.B.; Carpenter, S.R.; Dahm, C.N.; McKnight, D.M.; Naiman, R.J.; Postel, S.L.; Running, S.W. Water in a changing world. Ecol. Appl. 2001, 11, 1027-1045. [CrossRef]

4. Wang, L.; Fang, L.; Hipel, K.W. Basin-wide cooperative water resources allocation. Eur. J. Oper. Res. 2008, 190, 798-817. [CrossRef]

5. Wang, S.; Huang, G.H.; Zhou, Y. A fractional-factorial probabilistic-possibilistic optimization framework for planning water resources management systems with multi-level parametric interactions. J. Environ. Manag. 2016, 172, 97-106. [CrossRef] [PubMed]

6. Oelkers, E.H.; Hering, J.G.; Zhu, C. Water: Is there a global crisis? Elements 2011, 7, 157-162. [CrossRef]

7. Sun, S.; Wang, Y.; Liu, J.; Cai, H.; Wu, P.; Geng, Q.; Xu, L. Sustainability assessment of regional water resources under the DPSIR framework. J. Hydrol. 2016, 532, 140-148. [CrossRef]

8. Ge, L.; Xie, G.; Zhang, C.; Li, S.; Qi, Y.; Cao, S.; He, T. An evaluation of China's water footprint. Water Resour. Manag. 2011, 25, 2633-2647. [CrossRef]

9. Zhang, J.; Wang, L. Assessment of water resource security in Chongqing City of China: What has been done and what remains to be done? Nat. Hazards 2015, 75, 2751-2772. [CrossRef]

10. Lia, J.; Xib, R.; Wanga, A.; Zhangc, Y.; Huang, H. Early-warning system analysis for water resources security in Tianjin city. Desalin. Water Treat. 2014, 52, 2709-2716. [CrossRef]

11. Dai, J.; Qi, J.; Chi, J.; Chen, S.; Yang, J.; Ju, L.; Chen, B. Integrated water resource security evaluation of Beijing based on GRA and TOPSIS. Front. Earth Sci. China 2010, 4, 357-362. [CrossRef]

12. Liu, K.K.; Li, C.H.; Cai, Y.P.; Xu, M.; Xia, X.H. Comprehensive evaluation of water resources security in the Yellow River basin based on a fuzzy multi-attribute decision analysis approach. Hydrol. Earth Syst. Sci. 2014, 18, 1605-1623. [CrossRef]

13. Organization for Economic Co-operation and Development (OECD). OECD Core Set of Indicators for Environmental Performance Reviews; OECD: Paris, France, 1993. 
14. Friend, A.; Rapport, D. Towards a Comprehensive Framework for Environmental Statistics: A Stress-Response Approach; Statistics Canada: Ottawa, ON, USA, 1979.

15. Gentry-Shields, J.; Bartram, J. Human health and the water environment: Using the DPSEEA framework to identify the driving forces of disease. Sci. Total Environ. 2014, 468, 306-314. [CrossRef] [PubMed]

16. Hambling, T.; Weinstein, P.; Slaney, D. A review of frameworks for developing environmental health indicators for climate change and health. Int. J. Environ. Res. Public Health 2011, 8, 2854-2875. [CrossRef] [PubMed]

17. Chen, Y.; Li, B.; Li, Z.; Li, W. Water resource formation and conversion and water security in arid region of Northwest China. J. Geogr. Sci. 2016, 26, 939-952. [CrossRef]

18. Nezami, R.S.; Nazariha, M.; Moridi, A.; Baghvand, A. Environmentally Sound Water Resources Management in Catchment Level using DPSIR Model and Scenario Analysis. Int. J. Environ. Res. 2013, 7, 569-580.

19. Chu, H.D.; Xu, G.L.; Yasufuku, N.; Yu, Z.; Liu, P.L.; Wang, J.F. Risk assessment of water inrush in karst tunnels based on two-class fuzzy comprehensive evaluation method. Arab. J. Geosci. 2017, 10. [CrossRef]

20. Nazif, S.; Karamouz, M.; Yousefi, M.; Zahmatkesh, Z. Increasing Water Security: An Algorithm to Improve Water Distribution Performance. Water Resour. Manag. 2013, 27, 2903-2921. [CrossRef]

21. Sahoo, M.M.; Patra, K.C.; Swain, J.B.; Khatua, K.K. Evaluation of water quality with application of Bayes' rule and entropy weight method. Eur. J. Environ. Civ. Eng. 2017, 21, 730-752. [CrossRef]

22. Veettil, A.V.; Mishra, A.K. Water security assessment using blue and green water footprint concepts. J. Hydrol. 2016, 542, 589-602. [CrossRef]

23. Wang, W.S.; Jin, J.L.; Ding, J.; Li, Y.Q. A new approach to water resources system assessment-Set pair analysis method. Sci. China Ser. E Technol. Sci. 2009, 52, 3017-3023. [CrossRef]

24. Xia, X.F.; Sun, Y.; Wu, K.; Jiang, Q.H. Optimization of a straw ring-die briquetting process combined analytic hierarchy process and gray correlation analysis method. Fuel Process. Technol. 2016, 152, 303-309. [CrossRef]

25. Zhang, F.; Wang, L.; Su, W. Evaluation of land ecological security in Chongqing based on the matter-element analysis-DPSIR model. China Environ. Sci. 2016, 36, 3126-3134.

26. Zhang, F.; Wang, L.; Su, W. The safety evaluation of water resources based on DPSIRM conceptual framework in karst region. China Environ. Sci. 2015, 35, 3511-3520.

27. He, Y.X.; Dai, A.Y.; Zhu, J.A.; He, H.Y.; Li, F.R. Risk assessment of urban network planning in china based on the matter-element model and extension analysis. Int. J. Electr. Power Energy Syst. 2011, 33, 775-782. [CrossRef]

28. Cao, Q.; Chen, X.; Shi, M. Evaluation of water resources security in the urban area and regulating methods based on DPSIR: A case of Zhangye City. Resour. Sci. 2012, 34, 1591-1599. (In Chinese)

29. Wang, Q.S.; Yuan, X.L.; Zhang, J.; Gao, Y.; Hong, J.L.; Zuo, J.; Liu, W. Assessment of the Sustainable Development Capacity with the Entropy Weight Coefficient Method. Sustainability 2015, 7, 13542-13563. [CrossRef]

30. Zhang, F.; Wang, L.; Su, W.; Yang, Q. Evaluation on the safety of epikarst dualistic water resources by coupling model of entropy weight set pair. J. Hydroelectr. Eng. 2012, 31, 70-77.

31. Yang, Z.; Zhou, Q.; Guo, Y.; Su, W.; Zhang, F. Dynamic assessment of water resources security in karst area based on SPA-MC model-A case study of Guiyang city. China Environ. Sci. 2017, 37, 1589-1600.

32. Shang, C.; Wang, Q.; Hao, Z. Discussion on the reason, character and impact of the serious drought disease in 2009 and 2010 in Guizhou Province. China Water Resour. 2010, 17, 11-14. (In Chinese)

33. Liu, L.; Guan, D.; Yang, Q. Evaluation of water resource security based on an MIV-BP model in a Karst area. Water 2018, 10, 786. [CrossRef]

(C) 2018 by the authors. Licensee MDPI, Basel, Switzerland. This article is an open access article distributed under the terms and conditions of the Creative Commons Attribution (CC BY) license (http:/ / creativecommons.org/licenses/by/4.0/). 